\title{
Patent Ductus Arteriosus Detected on 64-Multidetector Row CT
}

\author{
Itsuki Nagata, Yuhei Shiga, Shin-ichiro Miura and Keijiro Saku
}

Key words: CT, ductus arteriosus

(Intern Med 52: 405-406, 2013)

(DOI: 10.2169/internalmedicine.52.9184)
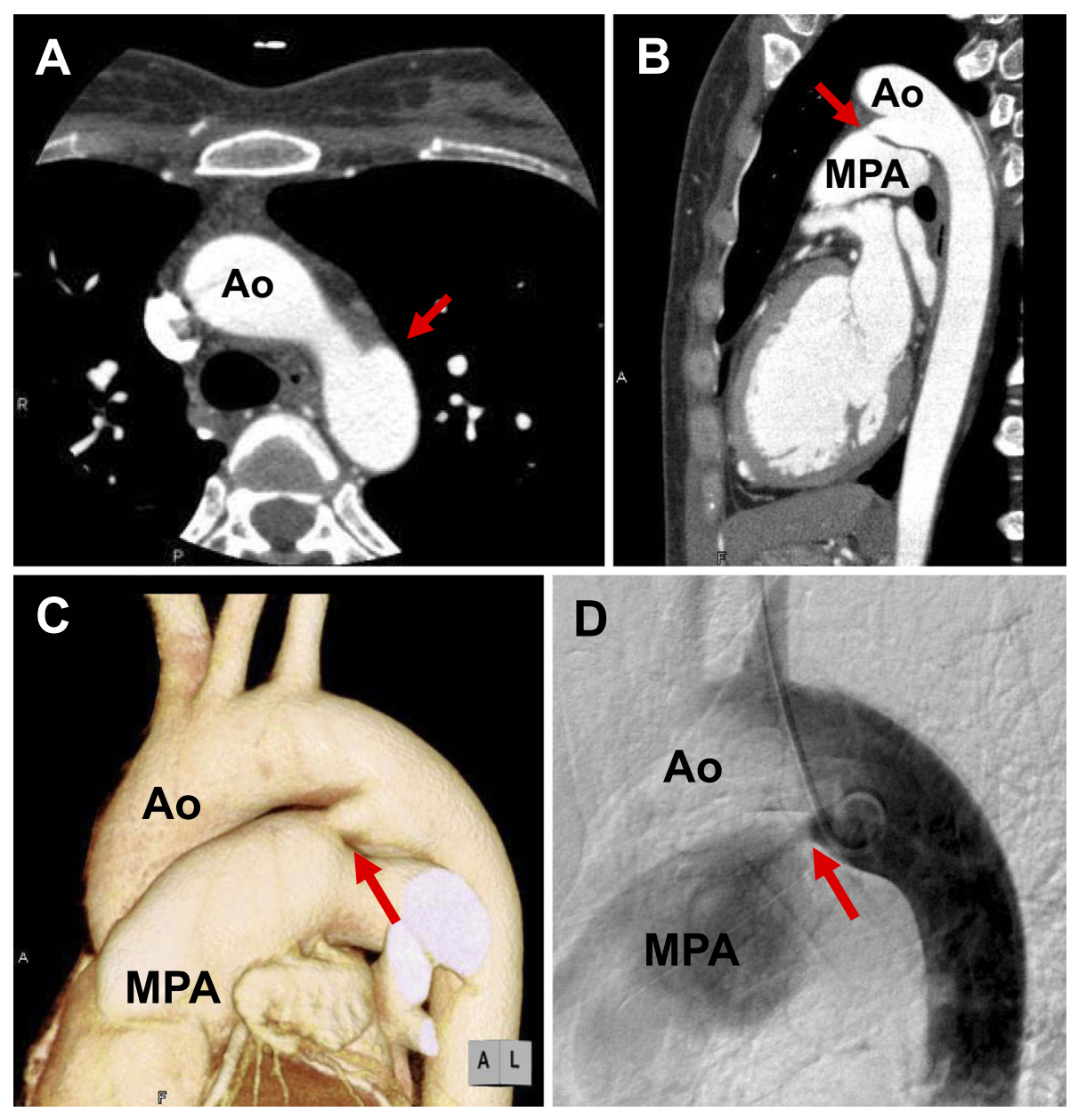

Picture.

A 35-year-old woman was referred to our hospital with the chief complaints of exertional dyspnea and palpitations. She had no history of hypertension, dyslipidemia or diabetes. She had a Levine grade 3/6 continuous murmur at the 2nd and 3rd left sternal border. Chest X-ray showed no car- diomegaly. Echocardiogram showed an abnormal flow from the aorta (Ao) to the main pulmonary artery (MPA). Further investigations were performed using 64-multidetector row computed tomography (CT) and a workstation. Axial and sagittal enhanced CT images (Picture A, B) were useful for 
demonstrating the size of the ductus arteriosus $(5.1 \mathrm{~mm})$. A volume-rendered image showed a ductus arteriosus extending from the aortic arch to the MPA (Picture C). Cardiac catheterization confirmed this finding, and it was easy to identify the enhanced blood flow from the aortic arch to the MPA (Picture D). The Qp/Qs was 1.13. Since the patient had experienced dyspnea and palpitations in addition to having a ductus arteriosus, transcatheter closure of the ductus arteriosus using the Amplatzer ${ }^{\mathrm{TM}}$ duct occluder was per- formed (1), and the patient's symptoms disappeared.

The authors state that they have no Conflict of Interest (COI).

\section{Reference}

1. Bentham JR, Thomson JD, Gibbs JL. Transcatheter closure of persistent ductus arteriosus in adults. J Interv Cardiol 25: 501-504, 2012.

(C) 2013 The Japanese Society of Internal Medicine http://www.naika.or.jp/imonline/index.html 